\title{
Silver Nanoparticles Obtained by Semicontinuous Chemical Reduction Using Carboxymethyl Cellulose as a Stabilizing Agent and Its Antibacterial Capacity
}

\author{
M. A. Pedroza-Toscano, ${ }^{1}$ S. López-Cuenca, ${ }^{2}$ M. Rabelero-Velasco, ${ }^{3}$ \\ E. D. Moreno-Medrano, ${ }^{4}$ A. P. Mendizabal-Ruiz, ${ }^{3}$ and R. Salazar-Peña ${ }^{1}$ \\ ${ }^{1}$ Departamento de Investigación, Centro Universitario UTEG, Guadalajara, JAL, Mexico \\ ${ }^{2}$ Instituto Tecnológico José Mario Molina Pasquel y Henríquez, Zapopan, JAL, Mexico \\ ${ }^{3}$ Departamentos de Ingeniería Química y Farmacobiología, CUCEI, Universidad de Guadalajara, Guadalajara, JAL, Mexico \\ ${ }^{4}$ Departamento de Ciencias Básicas, Aplicadas e Ingenierías, Centro Universitario de Tonalá, Universidad de Guadalajara, \\ Tonalá, JAL, Mexico
}

Correspondence should be addressed to M. A. Pedroza-Toscano; miguelpt@live.com.mx

Received 2 February 2017; Accepted 9 May 2017; Published 6 June 2017

Academic Editor: Piersandro Pallavicini

Copyright (C) 2017 M. A. Pedroza-Toscano et al. This is an open access article distributed under the Creative Commons Attribution License, which permits unrestricted use, distribution, and reproduction in any medium, provided the original work is properly cited.

Preparation of silver nanoparticles was carried out by semicontinuous reduction of $\mathrm{Ag}^{+}$ions at low temperatures. Silver nitrate was used as the $\mathrm{Ag}^{0}$ precursor, the carboxymethyl cellulose (CMC) as stabilizer and primary reducing agent, and sodium borohydride as reducing agent. Weight ratios of $1: 1$ and $1: 2$ of $\mathrm{AgNO}_{3}: \mathrm{CMC}$ were used for carrying out the reactions. Silver nanoparticles were characterized by UV-VIS spectroscopy, transmission electronic microscopy (TEM), and X-ray diffraction (XRD). The formation of silver nanoparticles was confirmed by XRD spectroscopy and by the presence of an absorption peak around $400 \mathrm{~nm}$ in the UV-visible spectrum. Unimodal size distributions of spheroidal nanoparticles were observed by TEM. Greater productivities than those reported by other authors were obtained with the advantage of using a lower temperature and minor reaction times. By using a higher $\mathrm{CMC} / \mathrm{AgNO}_{3}$ weight ratio or a higher concentration of $\mathrm{AgNO}_{3}$, AgNPs with larger average size were produced. Antibacterial activity of AgNPs against $S$. aureus and E. coli was determined by the agar disk diffusion method. The higher the AgNPs concentration, the larger the inhibition zone. The minimum inhibitory concentration (MIC) of AgNPs against S. aureus and $E$. coli was $5 \mu \mathrm{g} / \mathrm{disk}$.

\section{Introduction}

There is an increasing interest in the preparation and characterization of metal nanoparticles; among them, silver nanoparticles (AgNPs) are of particular interest due to their optical, electrical, and thermal properties. AgNPs have been used as catalyst [1-3], in nonlinear optical technology, as a bactericidal agent in apparel, footwear, cosmetics, and biomedical devices $[4,5]$, and in conductive applications and nanosphere lithography [6], among other applications. Due to their size, nanoparticles present unique and radically different physical, chemical, and biological properties compared to bulk materials; in addition to size, the properties also depend on their shapes, configurations, crystallinity, and structure [7]. One of the most important applications of silver nanoparticles is in the field of medicine as bactericidal agent. Bacteria can develop high resistance to antibiotics, resulting in an increase in recalcitrant infections. AgNPs are an alternative to typical antibiotics because their broad spectrum can counteract microbiological activity of Gram-positive and Gram-negative bacteria [5]. The antibacterial activity of silver nanoparticles depends on their shape, size, and size distribution; thus, control over these properties is necessary and can be done by using different synthesis methods, reducing agents and stabilizers [7]. 
AgNPs can be obtained by chemical, physical, and biological methods. In the chemical routes, silver ions in aqueous solutions are reduced, with or without stabilizing agents, by using electrochemical reduction, photoreduction in reverse and bicontinuous micelles, and chemical reduction [6, 8-10]. The physical methods include evaporation-condensation and laser ablation [11]. Biological methods employ microorganisms, plant extracts, or enzymes for the synthesis of AgNPs [12-14]. Plants are considered better option than microorganisms due to their availability, nontoxicity, and low cost. A large number of plants have been used for the synthesis of nanoparticles [12] and specifically to obtain AgNPs [14, 15]. In recent years, a derivation of cellulose, the carboxymethyl cellulose (CMC), has been used to synthesize AgNPs. CMC is water soluble, presents chemical stability, and is not toxic and, besides, being a reducing agent, it also can act as a particle stabilizer [16-18]. However, in order to carry out the $\mathrm{Ag}^{+}$ion reduction, temperatures much higher than room temperature or long reaction times are needed [12, 15-17, 19].

In this work, we report the obtaining of AgNPs by semicontinuous reduction of $\mathrm{AgNO}_{3}$ in aqueous solutions at low temperature $\left(0^{\circ} \mathrm{C}\right)$, using $\mathrm{NaBH}_{4}$ as reducing agent and carboxymethyl cellulose as stabilizer/reducing agent. The effect of $\mathrm{AgNO}_{3}$ concentration, $\mathrm{CMC} / \mathrm{AgNO}_{3}$ ratio, and dosage rate on particle size, shape, and antibacterial efficacy of AgNPs was studied.

\section{Materials and Methods}

2.1. Materials. Silver nitrate $\left(\mathrm{AgNO}_{3}\right)$ was $98.2 \%$ pure from Golden Bell; sodium borohydride $\left(\mathrm{NaBH}_{4}, 99 \%\right.$ pure from Fluka) and sodium carboxymethyl cellulose (CMC, Mw 90.000 from Sigma-Aldrich), were used as received. Deionized and triple-distilled water with conductivity smaller than $6 \mu \mathrm{S} / \mathrm{cm}$ was used.

2.2. Synthesis of Silver Nanoparticles. The syntheses of the AgNPs were carried out in duplicate using the formulations shown in Table 1, using a $250 \mathrm{~mL}$ jacketed glass reactor. The reactor had an inlet for feeding the sodium borohydride aqueous solution. The procedure for the reduction reaction started with loading the silver nitrate aqueous solution $(35 \mathrm{ml})$ into the reactor; then, CMC was added to the silver nitrate solution, and the temperature was reduced to $0^{\circ} \mathrm{C}$. A volume of either $0.326 \mathrm{~mL}$ or $0.246 \mathrm{~mL}$ of an aqueous solution of $\mathrm{NaBH}_{4}$ was added using a syringe, at 2-minute intervals for $90 \mathrm{~min}$ or $120 \mathrm{~min}$, respectively. When a concentration of $0.02 \mathrm{M}$ $\mathrm{AgNO}_{3}$ was used, the $\mathrm{NaBH}_{4}$ concentration was $0.056 \mathrm{M}$, and if a solution $0.04 \mathrm{M}$ of $\mathrm{AgNO}_{3}$ was used, the concentration of $\mathrm{NaBH}_{4}$ was $0.114 \mathrm{M}$. After completing the sodium borohydride addition, the reaction was allowed to continue for 30 more minutes. The molar sodium borohydride/silver nitrate ratio was $20 \%$ higher than the stoichiometric ratio.

2.3. Characterization of the Silver Nanoparticles. A volume of $0.05 \mathrm{~mL}$ of the AgNPs dispersion was taken and diluted to $20 \mathrm{~mL}$ with distilled water. To determine their particle size (JEOL JEM-1010) a drop of the dispersion was deposited on a
TABLE 1: Formulations for the syntheses of the silver nanoparticles.

\begin{tabular}{lccc}
\hline Sample & $\begin{array}{c}\mathrm{AgNO}_{3} \\
\text { molar } \\
\text { solution }\end{array}$ & $\begin{array}{c}\text { Reaction } \\
\text { time (min) }\end{array}$ & $\begin{array}{c}\mathrm{CMC} / \mathrm{AgNO}_{3} \\
\text { weigh ratio }\end{array}$ \\
\hline S1 & & 90 & 2 \\
S2 & 0.02 & 120 & 1 \\
S3 & & 90 & 2 \\
S4 & & 90 & 1 \\
\hline S5 & 0.04 & 120 & 1 \\
S6 & & & 2 \\
S7 & & & 1 \\
S8 & & &
\end{tabular}

copper grid, and the solvent was allowed to evaporate at room temperature before the grid was brought to the transmission electron microscope (TEM). TEM images of the nanoparticles were used for the size distribution measurements. Over five hundred particles were measured to obtain the particle average size and size distribution.

Diffraction patterns of the silver nanoparticles were obtained in a Siemens D-5000 X-ray diffractometer (XRD). For this purpose, the solvent of the dispersed nanoparticles was evaporated, and the nanoparticles were calcinated at $500^{\circ} \mathrm{C}$ for one hour to remove reaction residues. The residual powder was collected and weighed.

UV-VIS spectroscopy analysis was carried out in a PerkinElmer Lambda 25 Spectrometer. For this analysis, a volume of $0.1 \mathrm{~mL}$ of the reaction product was taken and diluted to $20 \mathrm{~mL}$ with distilled water; a $5 \mathrm{~mL}$ aliquot was used for the measurement.

Energy dispersive X-ray analysis (EDX) was performed on a TESCAN MIRA 3 LMU model. Silver powder was placed on a carbon tape and taken to the EDX for its analysis

2.4. Antibacterial Activity of Silver Nanoparticles. The AgNPs were tested for antibacterial activity by the agar disk diffusion method against the Gram-positive bacteria Staphylococcus aureus (ATCC 25923) and Gram-negative Escherichia coli (ATCC 25922). Briefly, after the pure cultures of bacteria were subcultured on nutrient broth, $0.15 \mathrm{~mL}$ (approximately $10^{7} \mathrm{CFU} / \mathrm{mL}$ ) of a bacterial suspension of a $0.5 \mathrm{McF}$ arland standard inoculum of each strain was spread homogeneously onto the individual tripticasein soy agar plates using sterile cotton swabs. Sterile filter paper disks $(6 \mathrm{~mm}$ diameter) impregnated with 10, 20, or $30 \mu \mathrm{g}$ of AgNPs were placed on the plates containing the nutrient and the bacteria. A disk charged with $10 \mu \mathrm{g}$ Streptomycin and another with pure water were used as positive and negative controls, respectively. The resulting growth of bacteria was observed after 24 hours of incubating the plates at $37^{\circ} \mathrm{C}$; the presence of inhibition zones, that is, the distance from the border of the disk to the edge of the bacterial growth, was measured. For each bacterial strain, three replications were performed.

Determination of minimum inhibitory concentration (MIC) is defined as the lowest concentration of the antimicrobial agent that inhibits the growth of the microorganism 
TABLE 2: Average diameter $(d)$ of the AgNPs.

\begin{tabular}{lcccc}
\hline Sample & $d(\mathrm{~nm})$ & $\begin{array}{c}d(\mathrm{~nm}) \\
\text { Scherrer equation }\end{array}$ & \% Ag wt (EDX analysis) & \% conversion \\
\hline SI & TEM & 12.57 & $94.1 \pm 2.15$ & 84.2 \\
S2 & $12 \pm 7.8$ & 15.87 & $95.4 \pm 2.46$ & 83.2 \\
S3 & $13.8 \pm 9.7$ & 27.80 & $93.3 \pm 2.35$ & 82.1 \\
S4 & $25.2 \pm 9.9$ & 31.55 & $94.9 \pm 2.44$ & 85.6 \\
S5 & $35.6 \pm 10.4$ & 19.24 & $95.6 \pm 2.70$ & 86.8 \\
S6 & $16.2 \pm 8.7$ & 14.45 & $93.8 \pm 1.98$ & 83.3 \\
S7 & $12.7 \pm 4.4$ & 28.07 & $96.4 \pm 2.53$ & 85.1 \\
S8 & $30.4 \pm 14.9$ & 44.74 & $92.7 \pm 2.81$ & 84.8 \\
\hline
\end{tabular}

after 24 hours of incubation [19]. AgNPs were tested to determine their minimum inhibitory concentration (MIC) and to evaluate their efficiency in controlling pathogenic bacteria ( $S$. aureus and $E$. coli). Sterile filter paper disks (6 mm diameter) impregnated with $1,2.5,5$, or $10 \mu \mathrm{g}$ of AgNPs were placed on the plates containing the nutrient and the bacteria. After $24 \mathrm{~h}$ of incubating the plates at $37^{\circ} \mathrm{C}$, the inhibition zone was measured.

\section{Results and Discussion}

Silver nanoparticles were synthesized using CMC as stabilizer and reducing agent. The reactions were carried out at $0^{\circ} \mathrm{C}$; this low temperature was used because particle growth is slower at lower temperatures; it favors stabilization during nucleation and promotes obtaining of more stable nanoclusters; furthermore, at low temperatures, CMC adsorption on the nanoparticles is larger, given more stability [20, 21]. CMC besides being a colloidal stabilizer also acts as a weak reducing agent $[22,23]$. When the CMC is added to the reactor, the $\mathrm{Ag}^{+}$ions are attracted to the negatively charged groups of the CMC $\left(-\mathrm{COO}^{-}\right)$displacing the sodium ions from the carboxylate groups and forming coordination complexes [16, 17]; then the $\mathrm{Ag}^{+}$ions couple with the polar hydroxyl groups $(\mathrm{R}-\mathrm{OH}$ or $\mathrm{R}-\mathrm{CH} 2-\mathrm{OH}$ ) of $\beta$-glucopyranose units, leading to the release of electrons from these groups and thus to the reduction of the $\mathrm{Ag}^{+}$ions; these $\mathrm{Ag}$ atoms serve as nucleation centers for the other $\mathrm{Ag}^{+}$ions $[16-18,22]$. A slight change of the transparent solution to a yellowish color was an indication that the CMC acted as a reduction agent to form AgNPs [17]. When the addition of the $\mathrm{NaBH}_{4}$ started, the solution began to turn black because of the reduction of the $\mathrm{Ag}^{+}$ions [10], and at the end of the addition a black and very stable colloidal solution was obtained. The product (a grayish-black powder) was recovered, obtaining conversions between 82 and $87 \%$ (see Table 2).

3.1. EDX Analysis. The EDX spectrum of sample S5 is shown in Figure 1, where an intense signal at $3 \mathrm{keV}$ can be seen, which is due to the Ag surface Plasmon resonance. Similar EDX spectra were obtained for all the samples. Table 2 shows that

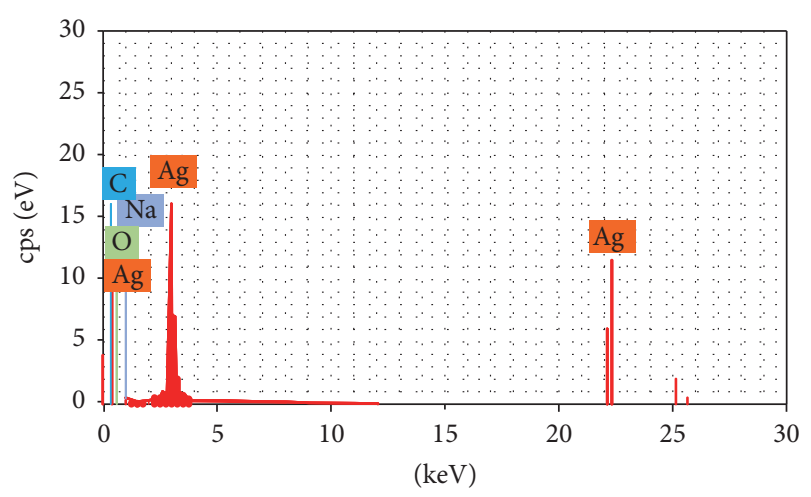

FIGURE 1: EDX spectra of silver nanoparticles (sample S5).

the percentage weight of Ag in the nanoparticles, obtained from the EDX spectra, is higher than $92.7 \%$.

3.2. UV-VIS Spectroscopy Analysis. Figure 2 show the UV-VIS absorption spectra of the silver nanoparticles obtained under two reaction conditions. An aqueous solution of carboxymethyl cellulose was used as the blank. The AgNPs spectra show absorption bell shaped bands and a maximum around $400 \mathrm{~nm}$ wavelength. This band is related to the surface plasmon resonance (SPR) of silver nanoparticles and has been used to confirm the reduction the $\mathrm{Ag}^{+}$to $\mathrm{Ag}^{0}[15,18]$. Furthermore, it is indicative of the spherical shape of AgNPs [16, 24], which was confirmed by transmission electron microscopy (TEM). It has been reported that a maximum absorption around $400 \mathrm{~nm}$ indicates particles with sizes between 15 and $40 \mathrm{~nm}[24]$.

3.3. X-Ray Diffraction Pattern. Figure 3 shows the X-ray diffraction pattern (XRDP) of the AgNPs obtained using the formulation S5. The XRDP of the AgNPs shows the major five characteristic signals of silver crystals (at 38.12, 44.21, $64.35,77.32$, and $\left.81.45 ; 2 \theta^{\circ}\right)$, which can be assigned to the (111), (200), (220), (311), and (222) planes corresponding to the face-centered cubic (FCC) phase of pure silver nanoparticles, respectively, according at the JCPDS File Number 04-0783. 


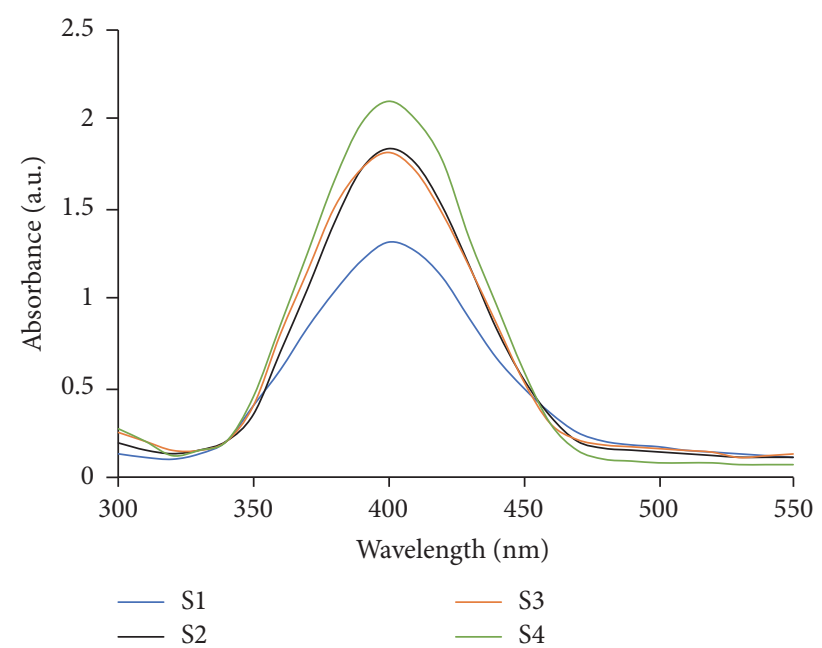

(a)

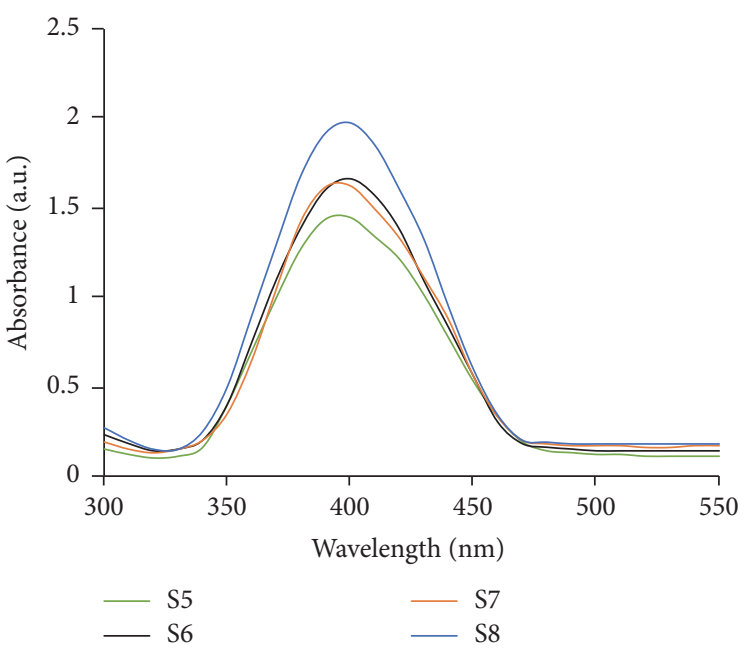

(b)

Figure 2: UV-VIS spectra of AgNPs obtained using (a) $0.02 \mathrm{M} \mathrm{AgNO}_{3}$ and (b) $0.04 \mathrm{M} \mathrm{AgNO}_{3}$.

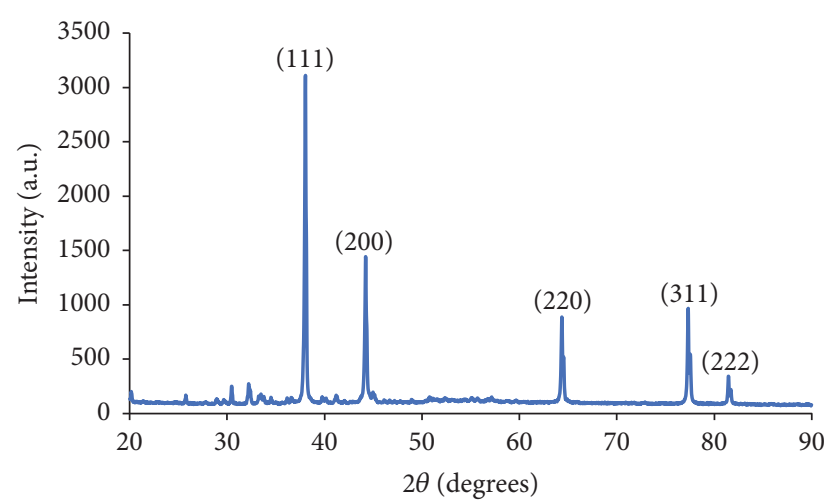

FIGURE 3: XRD of sample S5.

Similar XRD spectra were obtained for all the AgNPs. An estimation of the average crystal size of the particles obtained was made using the data from their XRDPs and the Scherrer equation:

$$
d=\frac{K \lambda}{\beta \cos \theta}
$$

where $d$ is the mean diameter of the nanoparticles, in $\mathrm{nm}$, $K$ is the dimensional factor (0.9), $\lambda$ is the X-ray wavelength $(0.154 \mathrm{~nm}), \beta$ is the line broadening at half the maximum intensity in radians, and $\theta$ is Bragg's angle. Table 2 shows the average diameters of the AgNPs calculated using the Scherrer equation where they range from 12 to $45 \mathrm{~nm}$ in agreement with the UV-visible spectra.

3.4. Transmission Electron Microscopy Analysis. The shape and size of the AgNPs were also determined by TEM. Figure 4 depicts representative micrographs of samples S1 and S5, along with their corresponding particle average diameters and histograms obtained by measuring over 500 particles; Table 2 shows the average diameter for the samples. The particles were quasi-spherical and the histograms indicate that there is a unique population, which suggests that each nanoparticle is formed of a single crystal [10]. The AgNPs obtained using the different formulations were quasi-spherical and presented similar histograms. A comparison of the average particle size of the AgNPs determined by TEM with those calculated from X-ray data shows that they are similar.

Nanoparticles obtained using a weight ratio of $\mathrm{CMC} /$ $\mathrm{AgNO}_{3}=1.0$ were larger than those obtained when using a higher weight ratio $\left(\mathrm{CMC} / \mathrm{AgNO}_{3}=2.0\right)$. It has been proposed that $\mathrm{CMC}$ stabilizes the metal by forming a protective negative charged layer by adsorption on the surface of the nanoparticles because - $\mathrm{COO}^{-}$has a strong binding with metals [21]; then AgNPs are stabilized by interaction with the CMC thus avoiding their coalescence [23].

Table 2 shows that, independently of the $\mathrm{AgNO}_{3}$ molar concentration and $\mathrm{CMC} / \mathrm{AgNO}_{3}$ ratio used, the nanoparticles obtained at the higher addition rate had a smaller diameter than those obtained at the lower addition rate. The larger particle size can be attributed to the longer reaction time that allows a greater aggregation of nanoparticles.

In general, larger particles were obtained using the higher $\mathrm{AgNO}_{3}$ molar concentration $(0.04 \mathrm{M})$. By increasing $\mathrm{AgNO}_{3}$ concentration, a greater number of nanocrystals are produced, and since their collision frequency increases, larger particles are formed [25].

Nanoparticles size distributions here obtained are similar to other ones obtained by wet chemical routes $(5$ to $80 \mathrm{~nm}$ ) $[15,16,19,26]$. However, due to the use of a higher molar concentration of $\mathrm{AgNO}_{3}$ and the presence of CMC that allowed the stabilization of the system, we obtained greater productivities than those reported by other authors with the advantage of using a lower temperature and minor reaction times. The productivity of AgNPs obtained here was around $0.115 \mathrm{~g}$ per $100 \mathrm{~mL}$ of reaction solution and $0.229 \mathrm{~g}$ per $100 \mathrm{~mL}$ of reaction solution, when using the 0.02 and $0.04 \mathrm{M} \mathrm{AgNO}_{3}$ solutions, respectively. Other authors have used molar concentrations 


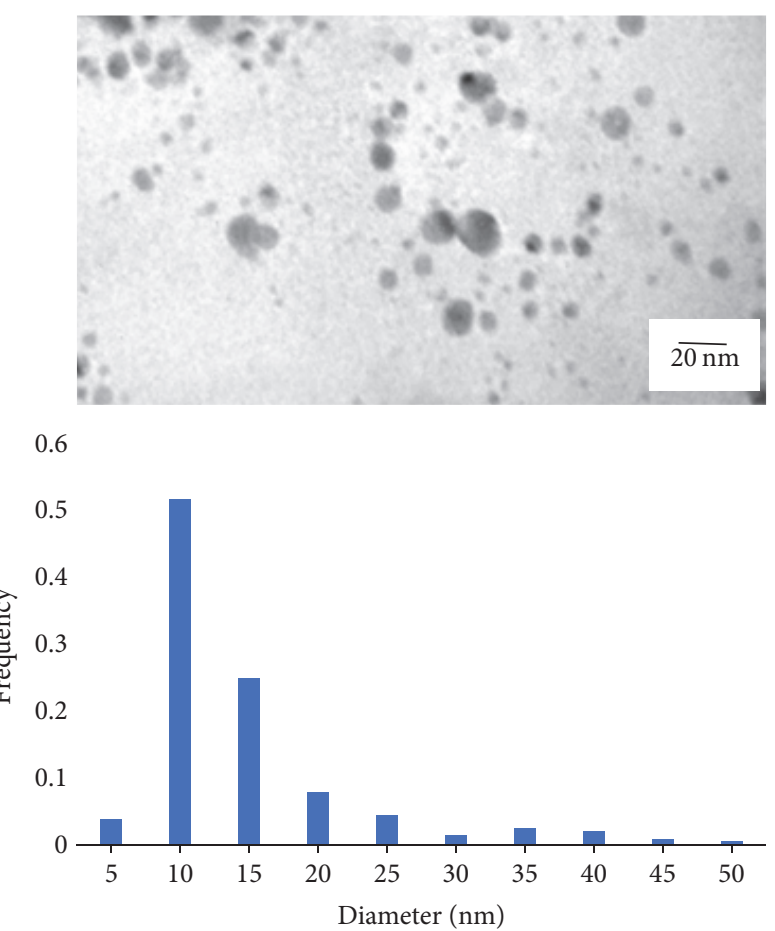

(a)
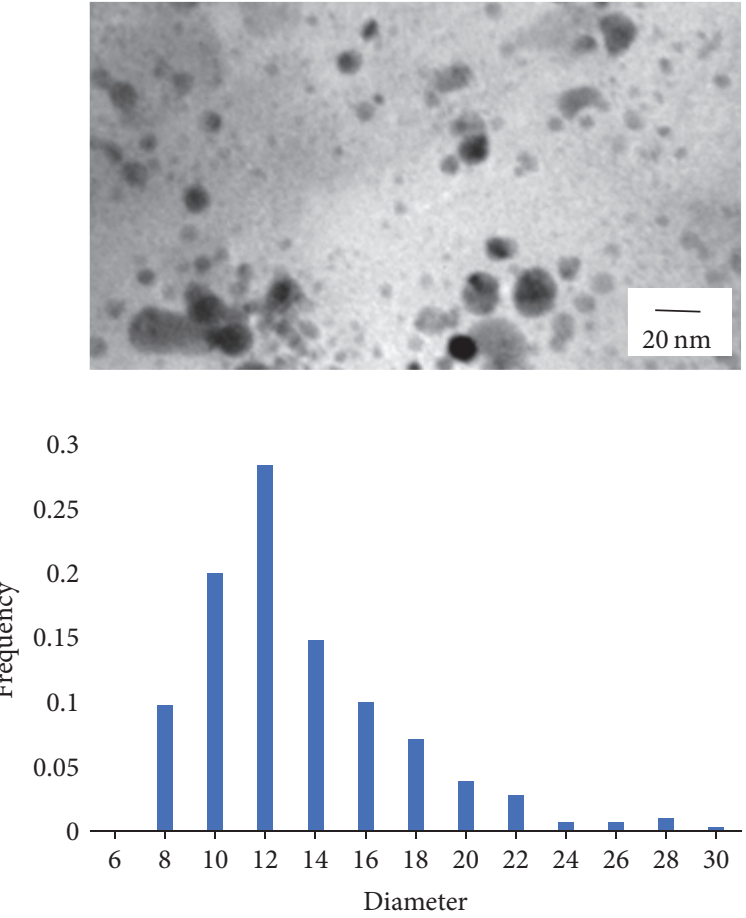

(b)

FIgURE 4: TEM micrographs and their histograms for AgNPs obtained from samples $\mathrm{S} 1$ and $\mathrm{S} 5$ using a weight ratio of $\mathrm{AgNO}_{3} / \mathrm{CMC}=1 .(\mathrm{a})$ S1: $0.02 \mathrm{M} \mathrm{AgNO}_{3}$. (b) S5: $0.04 \mathrm{M} \mathrm{AgNO}_{3}$.

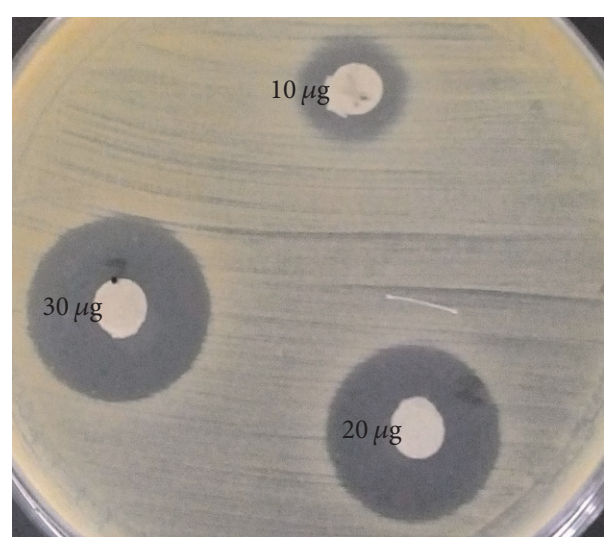

(a)

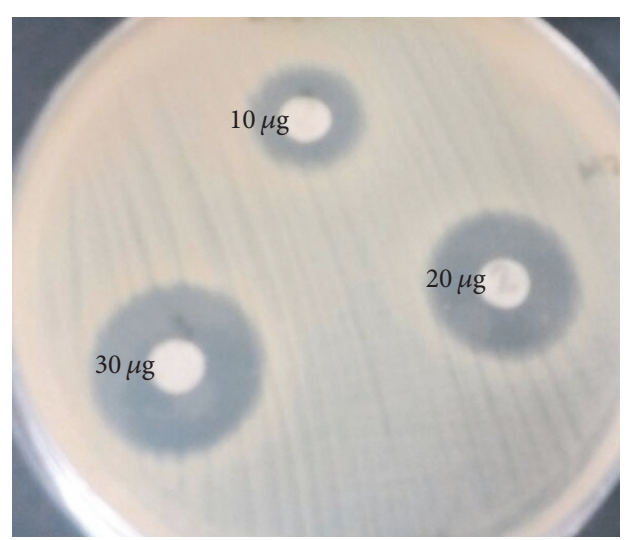

(b)

FIGURE 5: Inhibition zones (sample S5) around silver nanoparticles impregnated disks. (a) S. aureus; (b) E. coli.

of $0.01 \mathrm{M} \mathrm{AgNO}_{3}$ or less to obtain nanoparticles by chemical reduction in aqueous solution, resulting in maximum productivities lower than $0.1 \mathrm{~g}$ per $100 \mathrm{~g}$ of solution $[16,19,26-$ $28]$.

3.5. Antibacterial Activity of Silver Nanoparticles. The AgNPs showed antibacterial activity against both tested bacterial strains. Figure 5 shows the zones of inhibition for sample S5, and Table 3 shows the average distance of the inhibition zone for all the AgNPs. The higher the AgNPs concentration, the larger the inhibition zone (Table 3). At the highest AgNPs concentration studied, inhibition zones for $S$. aureus of $8 \mathrm{~mm}$ and of $6 \mathrm{~mm}$ for $E$. coli were observed. The positive control (antibiotic Streptomycin) showed inhibition zones of $5 \mathrm{~mm}$ and $8 \mathrm{~mm}$ for $S$. aureus and E. coli, respectively (Figure 6); the negative control (pure water) did not show inhibition zone. In this study, Table 3 shows that there is no effect of particle size on inhibition of growth of $S$. aureus and E. coli for the range of particle sizes studied. Raza et al. reported for E. coli similar results, since the decrease in AgNPs particle size had only a 
TABLE 3: Zone of inhibition ( $\mathrm{mm}$ ) of the silver nanoparticles.

\begin{tabular}{|c|c|c|c|c|c|c|}
\hline \multirow[b]{2}{*}{ Sample } & \multicolumn{3}{|c|}{ S. aureus } & \multicolumn{3}{|c|}{ E. coli } \\
\hline & $\begin{array}{c}10 \mu \mathrm{g} / \text { disk } \\
\mathrm{mm}\end{array}$ & $\begin{array}{c}20 \mu \mathrm{g} / \text { disk } \\
\mathrm{mm}\end{array}$ & $\begin{array}{c}30 \mu \mathrm{g} / \text { disk } \\
\mathrm{mm}\end{array}$ & $\begin{array}{c}10 \mu \mathrm{g} / \text { disk } \\
\mathrm{mm}\end{array}$ & $\begin{array}{c}20 \mu \mathrm{g} / \text { disk } \\
\mathrm{mm}\end{array}$ & $\begin{array}{c}30 \mu \mathrm{g} / \mathrm{disk} \\
\mathrm{mm}\end{array}$ \\
\hline S1 & $3.0 \pm 0.1$ & $7.0 \pm 0.1$ & $7.9 \pm 0.1$ & $2.7 \pm 0.3$ & $4.0 \pm 0.3$ & $6.1 \pm 0.1$ \\
\hline S2 & $2.9 \pm 0.1$ & $6.9 \pm 0.2$ & $8.0 \pm 0.2$ & $2.6 \pm 0.1$ & $3.9 \pm 0.3$ & $5.9 \pm 0.1$ \\
\hline S3 & $2.6 \pm 0.1$ & $6.8 \pm 0.3$ & $7.9 \pm 0.1$ & $2.7 \pm 0.2$ & $4.2 \pm 0.2$ & $5.8 \pm 0.3$ \\
\hline S4 & $3.0 \pm 0.1$ & $7.0 \pm 0.1$ & $7.8 \pm 0.3$ & $2.8 \pm 0.1$ & $4.0 \pm 0.1$ & $6.2 \pm 0.2$ \\
\hline S5 & $3.0 \pm 0.1$ & $6.9 \pm 0.2$ & $8.1 \pm 0.1$ & $2.8 \pm 0.2$ & $4.0 \pm 0.2$ & $6.0 \pm 0.2$ \\
\hline S6 & $2.7 \pm 0.2$ & $6.9 \pm 0.1$ & $8.0 \pm 0.1$ & $2.6 \pm 0.1$ & $3.9 \pm 0.1$ & $5.9 \pm 0.2$ \\
\hline S7 & $3.0 \pm 0.1$ & $6.9 \pm 0.1$ & $8.1 \pm 0.1$ & $2.8 \pm 0.1$ & $3.9 \pm 0.1$ & $5.8 \pm 0.1$ \\
\hline S8 & $3.0 \pm 0.2$ & $6.8 \pm 0.1$ & $7.9 \pm 0.1$ & $2.6 \pm 0.3$ & $4.0 \pm 0.0$ & $6.0 \pm 0.2$ \\
\hline
\end{tabular}

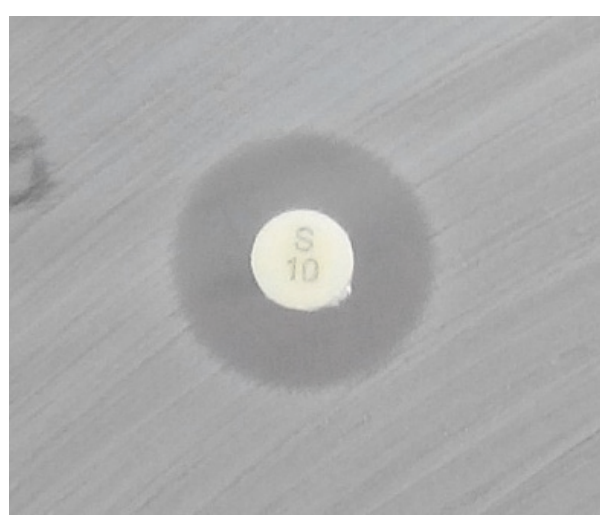

(a)

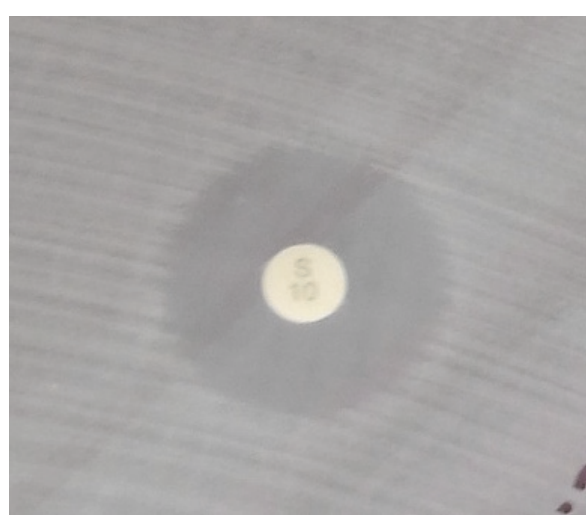

(b)

FIGURE 6: Inhibition zones around positive control (10 $\mu$ g Streptomycin) (a) S. aureus; (b) E. coli.

little increase in its inhibitory effect; however, smaller AgNPs had clearly a better inhibitory action against $P$. aeruginosa [28].

The minimum inhibitory concentration (MIC) of the AgNPs was evaluated. When disks containing 1.0 and $2.5 \mu \mathrm{g}$ of AgNPs were tested, no inhibition zone was detected. However, when disks with $5 \mu \mathrm{g}$ of AgNPs were used against $S$. aureus, an inhibition zone of $1.0 \mathrm{~mm}$ was observed and of $0.5 \mathrm{~mm}$ when tested against E. coli; the negative control (pure water) did not show inhibition zone. This indicates that $S$. aureus is more susceptible to AgNPs than the E. coli. Comparable results for inhibition of $S$. aureus and E. coli by AgNPs have been reported; for instance, Lkhagvajav et al. [29] when using AgNPs with sizes in the range of 20-45 nm obtained MICs of 2 and $4 \mu \mathrm{g}$ for $S$. aureus and E. coli, respectively; Mostafa et al. [19] found a MIC of $2.5 \mu \mathrm{g} / \mathrm{mL}$ for $S$. aureus when using AgNPs with sizes in the range of $42-58 \mathrm{~nm}$.

\section{Conclusions}

Very stable colloidal solutions of silver nanoparticles were obtained, by chemical reduction at a low temperature in a semicontinuous mode using CMC as a stabilizer/reducing agent and sodium borohydride as reducing agent. The characterization of the nanoparticles was carried out by TEM, UVVIS, and XRD. XRD and EXD confirmed the obtaining of
AgNPs. TEM images showed quasi-spherical AgNPs with unimodal distribution sizes in the range of 5 to $80 \mathrm{~nm}$. CMC proved to be an effective stabilizer agent. By using a higher $\mathrm{CMC} / \mathrm{AgNO}_{3}$ weight ratio or a greater concentration of $\mathrm{AgNO}_{3}$, AgNPs with larger average size were produced. Greater productivities than those reported by other authors were obtained with the advantage of using a lower temperature and minor reaction times. Both bacteria, S. aureus and $E$. coli, were inhibited by AgNPs. The higher the AgNPs concentration, the larger the inhibition zone. No effect of particle size on inhibition of growth of S. aureus and E. coli was observed for the range of particle sizes studied. The minimum inhibitory concentration (MIC) of AgNPs against $S$. aureus and $E$. coli was $5 \mu \mathrm{g} / \mathrm{disk}$.

\section{Conflicts of Interest}

The authors declare that there are no conflicts of interest regarding the publication of this paper.

\section{References}

[1] N. Pradhan, A. Pal, and T. Pal, "Silver nanoparticle catalyzed reduction of aromatic nitro compounds," Colloids and Surfaces A: Physicochemical and Engineering Aspects, vol. 196, no. 2-3, pp. 247-257, 2002. 
[2] H. Nakatsuji, H. Nakai, K. Ikeda, and Y. Yamamoto, "Mechanism of the partial oxidation of ethylene on an Ag surface: dipped adcluster model study," Surface Science, vol. 384, no. 1-3, pp. 315-333, 1997.

[3] M. Murphy, K. Ting, X. Zhang, C. Soo, and Z. Zheng, "Current development of silver nanoparticle preparation, investigation, and application in the field of medicine," Journal of Nanomaterials, vol. 2015, Article ID 696918, 12 pages, 2015.

[4] Z.-C. Xing, W.-P. Chae, J.-Y. Baek, M.-J. Choi, Y. Jung, and I.K. Kang, "In vitro assessment of antibacterial activity and cytocompatibility of silver-containing PHBV nanofibrous scaffolds for tissue engineering," Biomacromolecules, vol. 11, no. 5, pp. 1248-1253, 2010.

[5] E. Amato, Y. A. Diaz-Fernandez, A. Taglietti et al., "Synthesis, characterization and antibacterial activity against gram positive and gram negative bacteria of biomimetically coated silver nanoparticles," Langmuir, vol. 27, no. 15, pp. 9165-9173, 2011.

[6] H.-H. Shih, D. Williams, N. H. Mack, and H.-L. Wang, "Conducting polymer-based electrodeless deposition of Pt nanoparticles and its catalytic properties for regioselective hydrosilylation reactions," Macromolecules, vol. 42, no. 1, pp. 14-16, 2009.

[7] K. M. M. Abou El-Nour, A. A. Eftaiha, A. Al-Warthan, and R. A. A. Ammar, "Synthesis and applications of silver nanoparticles," Arabian Journal of Chemistry, vol. 3, no. 3, pp. 135-140, 2010.

[8] R. P. Bagwe and K. C. Khilar, "Effects of intermicellar exchange rate on the formation of silver nanoparticles in reverse microemulsions of AOT," Langmuir, vol. 16, no. 3, pp. 905-910, 2000.

[9] Y. D. Sosa, M. Rabelero, M. E. Treviño, H. Saade, and R. G. López, "High-yield synthesis of silver nanoparticles by precipitation in a high-aqueous phase content reverse microemulsion," Journal of Nanomaterials, vol. 2010, Article ID 392572, 6 pages, 2010.

[10] M. A. Pedroza-Toscano, M. Rabelero-Velasco, R. Díaz de León et al., "Preparation of silver nanostructures from bicontinuous microemulsions," Journal of Nanomaterials, vol. 2012, Article ID 975106, 7 pages, 2012.

[11] J. P. Abid, A. W. Wark, P. F. Brevet, and H. H. Girault, "Preparation of silver nanoparticles in solution from a silver salt by laser irradiation," Chemical Communications, vol. 7, pp. 792-793, 2002.

[12] R. Prasad, "Synthesis of silver nanoparticles in photosynthetic plants," Journal of Nanoparticles, vol. 2014, Article ID 963961, 8 pages, 2014.

[13] V. C. Verma, R. N. Kharwar, and A. C. Gange, "Biosynthesis of antimicrobial silver nanoparticles by the endophytic fungus Aspergillus clavatus," Nanomedicine, vol. 5, no. 1, pp. 33-40, 2010.

[14] C. Dong, X. Zhang, H. Cai, and C. Cao, "Green synthesis of biocompatible silver nanoparticles mediated by Osmanthus fragrans extract in aqueous solution," Optik, vol. 127, no. 22, pp. 10378-10388, 2016.

[15] Z. A. Ali, R. Yahya, S. D. Sekaran, and R. Puteh, "Green synthesis of silver nanoparticles using apple extract and its antibacterial properties," Advances in Materials Science and Engineering, vol. 2016, Article ID 4102196, 6 pages, 2016.

[16] M. A. Garza-Navarro, J. A. Aguirre-Rosales, E. E. Llanas-Vázquez, I. E. Moreno-Cortez, A. Torres-Castro, and V. GonzálezGonzález, "Totally ecofriendly synthesis of silver nanoparticles from aqueous dissolutions of polysaccharides," International Journal of Polymer Science, vol. 2013, Article ID 436021, 8 pages, 2013.
[17] M. N. Nadagouda and R. S. Varma, "Synthesis of thermally stable carboxymethyl cellulose/metal biodegradable nanocomposites for potential biological applications," Biomacromolecules, vol. 8, no. 9, pp. 2762-2767, 2007.

[18] A. A. Hebeish, M. H. El-Rafie, F. A. Abdel-Mohdy, E. S. AbdelHalim, and H. E. Emam, "Carboxymethyl cellulose for green synthesis and stabilization of silver nanoparticles," Carbohydrate Polymers, vol. 82, no. 3, pp. 933-941, 2010.

[19] A. A. Mostafa, S. R. M. Sayed, E. N. Solkamy et al., "Evaluation of biological activities of chemically synthesized silver nanoparticles," Journal of Nanomaterials, vol. 2015, Article ID 789178, 2015.

[20] Y. Zhou, H. Itoh, T. Uemura, K. Naka, and Y. Chujo, "Synthesis of novel stable nanometer-sized metal $(\mathrm{M}=\mathrm{Pd}, \mathrm{Au}, \mathrm{Pt})$ colloids protected by a $\pi$-conjugated polymer," Langmuir, vol. 18 , no. 1 , pp. 277-283, 2002.

[21] F. He and D. Zhao, "Manipulating the size and dispersibility of zerovalent iron nanoparticles by use of carboxymethyl cellulose stabilizers," Environmental Science \& Technology, vol. 42, no. 9, pp. 3480-3480, 2008.

[22] E. S. Abdel-Halim, H. H. Alanazi, and S. S. Al-Deyab, "Utilization of hydroxypropyl carboxymethyl cellulose in synthesis of silver nanoparticles," International Journal of Biological Macromolecules, vol. 75, pp. 467-473, 2015.

[23] A. V. Guselnikova, V. V. Visotskiy, O. Y. Uryupina, and V. I. Roldugin, "Formation of silver nanoparticles in solutions of carboxymethylcellulose," Protection of Metals and Physical Chemistry of Surfaces, vol. 45, no. 6, pp. 713-717, 2009.

[24] M. Andersson, J. S. Pedersen, and A. E. C. Palmqvist, "Silver nanoparticle formation in microemulsions acting both as template and reducing agent," Langmuir, vol. 21, no. 24, pp. 1138711396, 2005.

[25] W. Zhang, X. Qiao, and J. Chen, "Formation of silver nanoparticles in SDS inverse microemulsions," Materials Chemistry and Physics, vol. 109, no. 2-3, pp. 411-416, 2008.

[26] Z. Khan, S. A. Al-Thabaiti, A. Y. Obaid, and A. Al-Youbi, "Preparation and characterization of silver nanoparticles by chemical reduction method," Colloids and Surfaces B: Biointerfaces, vol. 82, no. 2, pp. 513-517, 2011.

[27] K.-S. Chou and C.-Y. Ren, "Synthesis of nanosized silver particles by chemical reduction method," Materials Chemistry and Physics, vol. 64, no. 3, pp. 241-246, 2000.

[28] M. A. Raza, Z. Kanwal, A. Rauf, A. N. Sabri, S. Riaz, and S. Naseem, "Size- and shape-dependent antibacterial studies of silver nanoparticles synthesized by wet chemical routes," Nanomaterials, vol. 6, no. 4, article 74, 2016.

[29] N. Lkhagvajav, I. Yasa, E. Celik, M. Koizhaiganova, and Ö. Sari, "Antimicrobial activity of colloidal silver nanoparticles prepared by sol-gel method," Digest Journal of Nanomaterials and Biostructures, vol. 6, no. 1, pp. 149-154, 2011. 

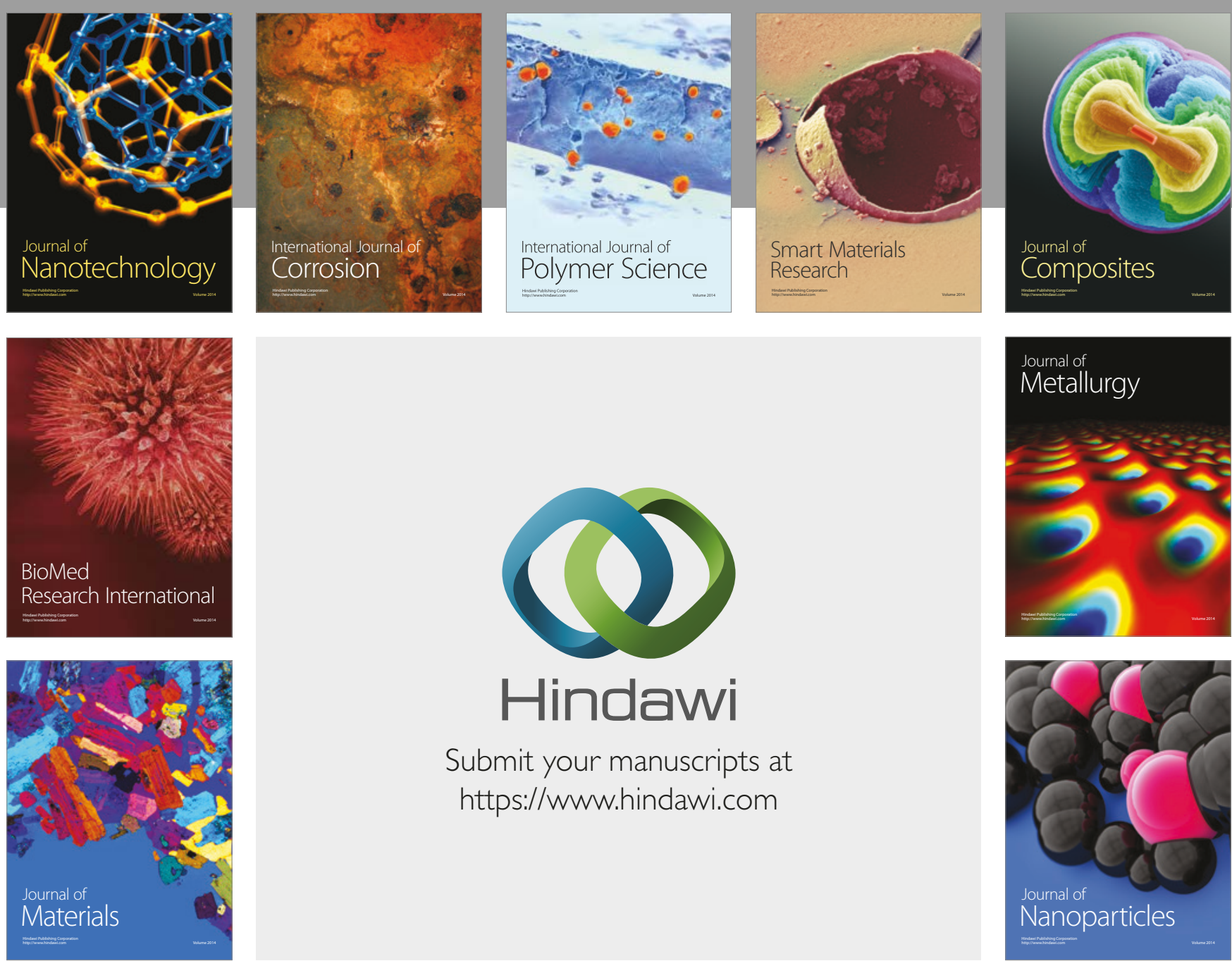

\section{Hindawi}

Submit your manuscripts at

https://www.hindawi.com


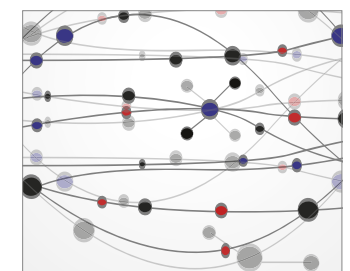

The Scientific World Journal
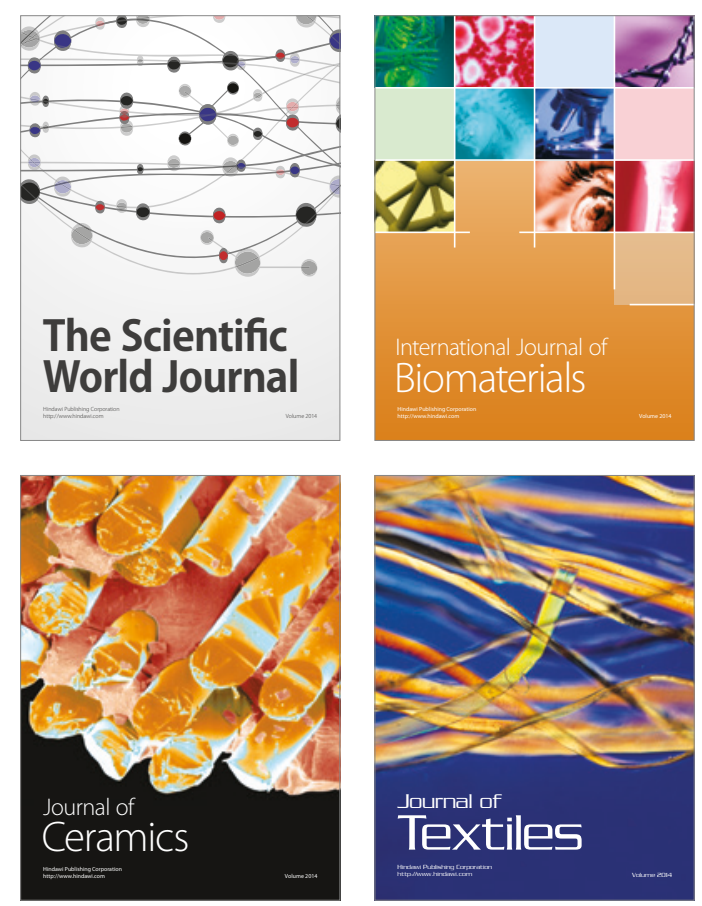